\title{
Images of Young Women in Hong Ke's Novel "Life Tree" and Their Values
}

\author{
Tai Kexiang \\ School of humanities, Xi'an Technological University \\ Xi'an, China \\ e-mail: Tkx6432@163.com
}

\author{
Gao Jianhong, Wang Hui \\ School of Foreign languages, Xi'an Technological \\ University \\ Xi'an China \\ e-mail: Waiyuxi-08@163.com
}

\begin{abstract}
By analyzing the fates of the four young married women - Ma Yanhong, Xu Lili, Wang Lanlan and Li Aiqin in Hong Ke's novel Life Tree, the paper points out the different paths of their growing from young girls into young married women, and explicates the perception of life that both Hong Ke and the four female characters in the novel have in common, that is, life first and career scecond. In order to convey the theme, Hong Ke sets two spaces - Xinjiang and Shaanxi, and makes a contrast between the two regional cultures through the images of Li Aiqin and Niu Luxi, her husband, and their stories, affirming the maganimity and pragmatism of the frontier culture and criticizing the parochialism and hypocrisy of the inland culture.
\end{abstract}

\section{Keywords- Hong Ke; Life Tree; Young Woman; Life First}

\section{INTRODUCTION}

The tree in "Life Tree" is not so much a legend as a metaphor. In the novel, the bubs and growth of trees are an analogy of human beings, precisely, the survival and growth of women; the mutual affinity of life and culture in diverse spaces is symbolized by the extending roots. In addition, the free lifestyle and the truth of life are enlightened by trees braving wind and rain and their natural growth law.

\section{LIFE ITSELF IS MORE IMPORTANT THAN RECEIVING EDUCATION}

The most impressive images illustrated in the novel are four young married women of Xin Jiang, who are saluted by Hong Ke via the Uyghur celebrations for young women. Ma Yanhong is an ordinary Xinjiang lady, with her life revolving around the downstream and upstream of the Four Tree river respectively before and after her marriage. The course of her life, as she dreamed when she was still young, should range from the Four Tree town, Wusu city, Kuitun, Shihezi, Changji, Urumqi, Kouli, Lanzhou, Xi'an, Beijing, Shanghai to abroad; however, unexpectedly, she had to confront the reversed reality that she still stayed at the upstream of the Four Tree river, instead of going out, which utterly transformed her outlook on life. "Not until I saw such clear water in the daylight from behind the bushes, did I have insight into the significance of being a maiden." She said so after she had been raped. She had once been a top student in the eyes of patriarches and teachers, who had expected her to go off to college. Unexpectedly, her destiny had been devastated by the unanticipated hazard. Other young ladies who suffered the same as she did would end up restraining themselves and making do with the rest of their life. But she came round the idea that the only thing she desired to accomplish was to be a good girl; conversely, the dream of attending university has become unimportant. "Owing a house or a home was my ultimate fantasy at that time. "It's on the right track, right?" "Is it a bright future indeed?" she asked her intimate classmate $\mathrm{Xu}$ Lili, a representative of popular thinking. Her idea was backed up by her parents, and later understood by $\mathrm{Xu}$ Lili, and furthermore was identical with Chen Hui's view of life, who was Wang Lanlan's husband. "Life itself is more important than receiving education." said her father Ma Laixin. Chen Hui inscribed life motto to his proud disciple Ma Liangliang, who was Ma Yanhong's younger brother, before he commenced his college life. "Study hard and get educated in your freshman year; find a girlfriend in your sophomore year; sublimate the affection into love in your junior year; keep subliming your love in your senior year till you marry her and love your wife forever." Ma Liangliang had no notion what it meant. Chen Hui told him, "You would perceive what I mean now." "Be aware that "the life motto is much more vital than your majors. It can assist you in avoiding detours in advance. Happiness is primary and career is secondary." He remarked and repeated time and again. A similar idea flashed into $\mathrm{Ma}$ Laixin's mind after his son's weird disease was cured. "Nothing is more critical than getting married. My son has recovered, and may take a wife. It does not matter whether he can attain a master degree, doctorate or go abroad. It's not bad for him to abandon receiving higher education and to be a farmer. To a man, the most important is to get married and have children."

All this derived from the revelation of nature. For $\mathrm{Ma}$ Yanhong, it is the baptism of the sunny rain. "Sparrows are twittering on the top of walls and roofs; branches of trees are swooshing loudly; sheets of sunshine are droping and piling up till the windowsills and the roof of the house either; sunlight is still scattering ceaselessly...the house in the brilliant sunshine is so warm." It is the purity and energy of nature that bestow enlightenment and rebirth on us." I have never caught sight of such clear water here. Not until I saw such clear water in the daylight from behind the bushes, did I have insight into the significance of being a maiden...the stream and the spring reminds me that I used to be a fairly pure virgin." Ma Yanhong said, "A girl is likely to get married when sunny rain drops on her." She came back home drenched. People in the village gazed at the girl and detected a sweet fragrance from afar...That's the scent of an 
untouched virgin. "All that Ma Yanhong simply wants is to be a fairly pretty girl and attending university is not absolutely essential any longer." Such perceptions might be viewed as a sort of snobbish concept of life; nevertheless, it can also be viewed as naturalness when people get lost in the pursuit of fame and wealth.

\section{INTERESTS ARE INFERIOR TO RESPECT FOR ALL TIME}

$\mathrm{Xu}$ Lili, one of Ma Yanhong's classmates, has just accomplished the goal of developing away from home which had been planned yet unfinished by Ma Yanhong. She became a secularly established figure as being a prestigious reporter after graduation from college. She came to become compunctious after she ran into Ma Yanhong and knew her peculiar experience, particularly, her abrupt psychological change. To herself, she yielded accomplishment definitely, but she was a loser in her family. She disregarded and even isolated her spouse unconsciously. Her unwillingness to open up her heart to him brought about an estrangement between them. Permanent untrustworthiness and untimely premature he undergone accounted for his death of depression accordingly. He didn't understand until his death that it was because Ma Yanhong's tragedy had posed a sharp impact upon his wife during high school that his wife was consistently addicted to the literature world so as to escape from the reality. "Xu Lili led another life apparently. No one could step into her inner world, not mentioned her dreamland." She spent half of her lifetime in such illusion which she hadn't noted. For a long time, she had given tacit consent to being said to be reserved, proud, and elegant by the people around her. Not until her husband died, did she wake up and recognize her regret, compunction and distress. Her escapism generated her husband's grief and prosiness; hence, he looked much more hoary and old exteriorly than peers, in sharp contrast to her elegance. Upon realizing this, her outlook on life was vacillated. The lifestyle she had stuck to did not make her happy and hurt her husband because of her brutal blame intentional and unintentional. Her husband Du Yupu was frequently called names as donkey. If a Xinjiang woman calls a man names such as donckey, she means that he is a draught animal. What he merely concerns is to have relations with women instead of venturing into their heart, regardless of their inward emotions. Her discontent with her husband might not mean the genuine implication of the swearword of Xinjiang people. It was nothing but a kind of complaint, which, however, engendered fatal damage to his husband. Du Yupu took it seriously and regarded it as contempt. Direct impact of the word "the donkey" upon him, as is quoted from the novel, was tremendously frustration.

$\mathrm{Xu}$ Lili pondered over the origin of his husband's misery from his gloomy facial expression and comprehended her horrific hurt to her husband. "Xu Lili witnessed the loneliness and wretchedness on Du Yupu's distressed face she detected both him and his soul from his sad-looking face.

Her husband was not appreciated by her and never stepped into her inner heart. She was undoubtedly lamentable, which couldn't be offset by her refulgence of career. She deemed she was inferior to Ma Yanhong, a contadina who even didn't attend university and was raped. Thus, she started to change and to remedy her defects. She transformed her indebtedness to her husband into showing filial obedience to her parents-in-law. Over the years, she has been immersing herself in recalling of her husband. She took every chance to remote He Tian, and sent her son to visit her parents-in-law on every vacation and got him back when the school term started. It is fascinating that her second husband threw himself at her feet due to such specific spirit of moral purity - a typical personality in literary classics resulting in Du Yupu, her first husband's tragedy.

Transformation from a virgin to a wench is a course of mental and physiological maturity and growth. To be a good wife, an excellent mom, and a superior daughter-in-law is superposed standing of a Uyghur good wife.... According to Uyghur legend, when marrying off his daughters, Genghis Khan said to them: "There are three husbands within a wife's heart: parents-in-law, husband himself and the kids." He also compared Husband to a tiger. A tiger had three shadows. The middle shadow was the tiger's real body, and the left and right shadows were the tiger's soul. A superior wife should distinguish her husband's exterior which was located in the middle, with kids and parents-in-law on the both sides. Xu Lili took nearly half of her lifetime to be fully aware that a pretty wife should ardently love both her husband and his family members.

Wang Lanlan was the practice teacher of Ma Yanhong and $\mathrm{Xu}$ Lili, both of whom were of her own age. Her life was infected by Ma Yanhong's incident as well. She always associated offence with rape and never revealed her secret, which she couldn't forget, to her husband.... She associated rape with offence, in turn with brutality, awkwardness and inner viciousness, all of which were disgusting and antipathetic to her."

It was just beacause Wang Le was awkward or somewhat discourteous that her love affair with Wang Lele failed. On the contrary, Chen Hui's esteem and elegance made her married to Chen Hui. Nevertheless, her husband knew so much about her that she has little privacy, which was a superficial reason for their long term separation. It was having no privacy, which was once envied by $\mathrm{Xu}$ Lili because she and her husband failed to do so, that was exactly detested by Wang Lanlan conversely, "He had me figured out, even my dream." "Is that telesthesia, right?" "Is it a fantastic marriage bonds?" "The mutual affinity is too perfect, elaborate and even ideal, which you have never sensed yet."

Genuine rapport conjugal relation appreciated by ordinary people is miserable and even intolerable in Wang Lanlan's view, why? This is consistent with her principle that she loathes rapeand discards disrespect toward women. Chen Hui is so incomparably smart that he can read people's furtive minds. As the novel describes, he knew the Eight Diagrams and could tell fortune. So, after he sensed her wife's emotional infidelity, he could imitate the motion, poise of her wife's lover and had relation with her in and out of sleep to please her without being discerned.

Wang Lanlan sensed how much harm her husband had done to her when her husband's despicable act was revealed 
by his unconscious words; therefore, she kept out of him counsciously. She disclosed to Xu Lili: Her being a teacher in the countryside voluntarily was not so magnificent as what had been publicized. Practically, her true purpose was to stay away from her husband."

They had same reflections on life - to be one with determination and aspiration - even a "cold war" broke out between them. "You are a conscientious person. The world doesn't belong to those who have power or those who have fortune, but it belongs to those who are observant and conscientious." His master of the Eight Diagrams remarked when he was ready for accepting him as his apprentice.

"I inform you that the world belongs to those who are observant and conscientious." Wang Lanlan said so with the similar insight but the absolutely diverse premise of the words.

\section{WOMEN WOULD MATURE AND BECOME THE MOST BEAUTIFUL UNTIL THEY GET MARRIED.}

Li Aiqin was slightly different from the former characters. First, she was elders compared to others. She was Niu Luixi's wife, who was a fellow soldier of Ma Yanhong's father, according to the novel. Second, she was not influenced by Ma Yanhong's suffering, but by the regional difference between Xinjiang and Shaanxi since she was a local of Xinjiang while her husband is a native in Qi Shan, Shaanxi province. Her minor misery from her sisters-in-law and brothers-in-law made her somewhat similar to the former wenches mentioned above. She was, undoubtedly, forbearing, enduring and self-sacrificed as Wang Baochuan. Loving kids and showing filial piety to parents were the characteristics that they had in common; they were also the key factors attributing to their marriage and their love never faded away after divorce. What he memorized was not kids' names but their features, say, eyes, ears, noses, tongues, arms, legs and hair, even smell of them, which was so vivid and true and they were all relative to lamb, calf and pony - that was so touching to her. "I have never seen such a nice person who loves his mom that much."

She experienced in person that her mother-in-law was teased by her sister-in-law who reckoned her mind to frighten her to yield, thus she could domineer over her. She volunteered to pick her up aside and kept her rested on her laurels. Her mother-in-law virtually had lived in ease and comforts, which she had never enjoyed in her lifetime, for three years in Xinjiang. Her son and daughter-in-law showed filial obedience to her. Furthermore, the neighbors, including minorities, respected and cared for her. This was her prime time she spent in all her lifetime. However, it didn't last long. Her third son'wife began to play trick. They made an excuse for requesting her back to look after their son. Both Li Aiqin and her mother-in-law were aware obviously that she was so narrow-minded that she envied of prosperous life of her elderly brother-in-law and attempted to exert pressure on the family of Niu Luxi. "That goblin felt uneasy and rather unpleasant when she witnessed that I was well off in comfort...I gave birth to and brought up three children while she barely had one to bother me. No way!" Li Aiqin commenced remitting to the younger brother-in-law, pinching and scraping, so as to hinder her mother-in-law back home. Yet the old biddy was compelled to return on the ground that his son was ill and in hospital and missed his grandma so much. They had no option but to send her back reluctantly. Plus, the couple was still discontent with it and extorted money from their elderly brother time and again on the excuse that mother was in poor health. What's more, Niu Luxi and his wife were obliged to transfer to inland because they said that all the sons should take full responsibility and obligation to take care of their mom. "What Li Aiqin worried deeply about occurred consequently. A joint letter written by his elderly brother, sisters and uncle said that the whole family of Niu Luxi should transfer back to inland because all of the sons and daughters had obligations to take care of their mother in turn .They said he was so idle that he should take responsibility to show filial piety instead of remitting money to his mom merely. What he should do was to serve her considerately and endeavor to take care of her diet and daily life.

A bold decision of divorce was made when Niu Luxi was compelled reluctantly to transfer back. "You are such a fool. Why don't you consider the situation that there is no less than one daughter-in-law indeed but there is only one mom actually? I have made a pledge to serve her all the time. You should serve her if I fail to do so. You can leave me behind when you run into a fair woman. I will be here waiting for you until you get a new and pretty one. You could remarry me and transfer to Xinjiang after nourishing your mother in her old until her death. It is a little bit effortless to transfer you from Shaan Xi to Xinjiang than transfer conversely."

The perfect couple was broken up and they didn't remarry to the end, although the old biddy passed away. Normally, he could return back to Xinjiang to be reunited with Li Aiqin; nevertheless, he didn't. His brothers and extended family drove him mad. He was bullied by them all his life and all his savings and kinship were both invested and ruined. He was unwilling to go back to remarry his wife for he felt ashamed even when he was almost recovered after therapy. Accordingly, it was a dilemma to Li Aiqin that there was no alternative for her to marry other men and there was little chance to accompany her ex-husband as well.

Cultural connection and communication of lives in diverse spaces could be illustrated by the example of $\mathrm{Li}$ Aiqin to broaden the novel's perspective. The stories told in "Life Tree" took place in Xinjiang, but they have to be closely related to inland inevitably because of the background of the characters. Diversity of culture between the inland and the frontier region is demonstrated in the novel. They are linked together by their roots but their branches reach out in different directions. The gist of the novel, as a consequence, is reinforced that every woman has different values, but their comprehension of life is similar.

\section{CONCLUSION}

According to Hong Ke, women would mature and become the most beautiful until they get married. The utmost comprehension of life is the implication of outlook on life, except for being mature physiologically and psychologically. 
Life is the top priority indeed while career ranks the second; being a superb wife is much more vital than being individual; interests are inferior to respect for all time. "Life Tree" conveys these eternal yet often forgotten secrets to the readers through different fates of the four young married women exemplified in it.

\section{ACKNOWLEDGMENT}

Shaanxi social science fund: Ten years of new century, shaanxi long novel research, project number: 10k147

\section{REFERENCES}

[1] Hong Ke. "Life Tree" [M] Beijing October Literature and Art Publishing House , 2010

[2] Hong Ke. "Looking for Hometown from Two Views" [N]. Guangming Daily

[3] Hong Ke. "Contact with the Earth" [J].People's Literature. 2002(05)

[4] Jiang Guangping. "I Grasped Two Worlds - My Dialogue with Hong Ke" [J]. Literature Education, 2010, (07):4-10.

[5] Ding Zhe. "On Life Tree" [D]. Shaanxi Normal University, 2012. 